\title{
Information and Communication Technology and Implication for Sports Management in Nigerian Universities Sports Organizations in the 21st Century
}

Iheanacho, Samuel B. C.

\author{
Department of Human Kinetics \& Health Education \\ University of Calabar,Nigeria
}

Okoro Rufus

Dept. of Physics(Electronic/Computer Unit)

University of Calabar,Nigeria

O’Neill Charles Bassey

Dept. of Human Kinetics \& Health Education, University of Calabar,Nigeria

Doi:10.5901/mjss.2013.v4n5p113

\begin{abstract}
This paper focuses on the concept of sports, sport management, sport management system, information and communication and the underlying factors as regards to Information and Communications Technology. It dwelt on its benefits in sport management in Nigeria, Universities sports Association and as Technological revolution as applied to the administration of sports; importance /need for the internet services in specific management functions such as training, online registration, competition entries, membership database, marketing, and Ecommerce as vehicle for universities to participate in sports through lower priced equipment. Accordingly it highlighted the requirements for the set - up of Information Communication Technology centre for sports management in a University. Finally recommendations were made on ways in which Information Communication Technology can enhance sports management for those charged with the responsibility of managing sports in Nigerian University Sports Association.
\end{abstract}

Keywords: Sports, Management, Information, Technology.

\section{Introduction}

The pace of Information and Communications Technology Advancement in the $21^{\text {st }}$ century is seen as a welcoming development. Nigeria as a developing nation sees Information and Communications Technology as a bedrock for the development of her economy in terms of sports management and globalization. Nigerian Universities stands to benefit from this global trend because sports is seen as an instrument to propel brotherhood and friendship among member nations and the world at large. This calls for an objective and effective information technology management. Information is very vital for managers of sports organization or outfit. It allows for management of resources effectively and also communicate with stakeholders. Sharing information with those who deliver services namely paid staff and volunteers at all level is very important in sports organization. Information technology refers to machine technology that is controlled by or used information. This information are increasingly coming from electronic sources (e.g handsets - Information Technology); and may be too much at a time for a sports administrator to control; some at times maybe of dubious value. Therefore good information is highly necessary in sports management. For of information to 
be deemed good, it must possess the following - Completeness (helps in decision making; Relevant to the problem at hand for decision to be taken Timeliness - at the right time; Accurate for its intended purpose; must be very clear and it should not contain jargons O'Brien (2004) defined information as data that have been converted into meaningful and useful context for specific end use. Information is a proceed data placed in context that gives it value for a specific end user while technology has to do with a new innovation of utilizing modern equipment to replace obsolete ones in order to accomplish a given task. Jessup and Valacich (2004) opined that technology is any mechanical and/or electrical means to supplement, extend or replace human, manual operations or devices.

Communication is the transmission of data/information, from the sender to the recipients through the aid of transmission media. The transmission media are hardware and software facilities which aid in transmission of information, in this arrangement, cables and microwave devices come into play. Again Jessup and Valacich (2004) defined telecommunication as the digital data, voice, fax sound and video from one location to another over some type of network.

\section{Concept of sports}

Sports is a global social giant which brings together people from different social, political and religious background for the attachment of a goal. It is a natural part of human life for competitive or recreational purposes. Oluruntola and Achugbu (2002) opined that sports is an insitutionalised physical activity which operates by rules fixed externally. Sport today is globally accepted as an instrument for promoting peace, unity and understanding among nations. Sports is education, is life, and above all character moulder by all standard (Iheanacho 2001). Given the increasingly significant role of sports in modern society, sportsmen and women are more than ever before seen as a mirror of their respective societies. Loy (1990) opined that sports is painful and competitive, requiring physical skill, strategy and chance as well as physical process.

\section{Concepts of management/system}

The concept of management is derived from managing which is one of the most vital human activities that take place in all sports organizations. It is the responsibility of any sport manager to ensure that members of their organization put in their best towards attainment of set goals of the organization. Management is essential to sports managers and administrators, because sports in an institution, which can only thrive if handled by competent person with sports management skills. In other to exploit the best in every member who participate in any sports the manager has the responsibility of understanding the people their personal needs, emotional needs and thus encourage growth amongst members. Management therefore is concerned with the task of determining the objectives of an organization and then guiding the people and other resources of the sport organizational system towards the attainment of these goals management does not exist in a vacuum but in a system with human and material resources Ikhioya (2001) concluded when he defined management as all the activities involving the incorporation and coordination of men, money, materials and machines in time and space for the successful accomplishment of objectives ends.

\section{Sports management in Nigerian universities}

Generally speaking, sports management is very essential to sports administrator, Directors and even coaches in Universities Games/Sports. It is the bedrock for sports development in all tertiary institutions. It is responsible for the smooth running of various sports in terms of planning, organizing, directing, co-ordinating and financing all aspects for meaningful result in sports. According to Ikhioya (2001) sports management is an applied management which focuses on ensuring efficiency and effectiveness in the utilization of human, materials monies and machines so as to articulate adequately all managerial functions with the set goal being 
to optimize output from input process and thus bring about productive outcomes with guaranteed satisfaction from all actors in the sporting process. Sports management aims at optimizing performance while taking into consideration the past, the present and the future for success. It is a means to an end but not and end itself, many authorities of diverse background are involved in sports management visa versa the attitudes, journalist, sports commentators. All these in one way or the other wants to be recognized. These people must be moulded by sports administrators/manages for success to be achieved at the end of the day.

In our Universities we have intramural, extramural and intercollegiate sports management programmes and they receive adequate attention. According to Bucher (1984) intramural and extramural sports programmes are basic to sound education. In spite of the above, each University in Nigeria has incorporated sports into the body of its administrative management system. Some Universities operate the sports committee system were sports policies are formulated and backed up to organize meetings and competition; other with academic bias in physical and health education decide to manage their sports programmes through their departments; other also operate from the office of Dean of Students Affairs; yet other have a Directorate of Sports to manage their sports programme. This implies that sports management in Nigeria Universities varies with each University.

\section{Sports management information system}

Wu and $\mathrm{Wu}$ (2005), opined that a system is a set of interrelated components that function together to achieve a common goal. Management of information technology in sports encompasses the development, use management and study of computer based information system in the organization of sports in the Universities and the society at large. The management of sports organizations for example Nigerian University Games Association (NUGA); West African University Games (WAUG) and Nigerian Universities Staff Games (NUSSA); and others, are becoming more complex and we are increasingly relying on information technology to help. There are several forms of information technology that need to be used today in sports organization in Universities. They include: Telephones - fixed mobile; computers - file servers; desktops and laptops; cameras - digital; phone, webcam; video - tape; numeric; streaming video; internet satellite, cable, wireless; television - cable, satellite storage - disks, CDs DVDs, USB keys; net - works opital fibre cables, wireless and blue tooth.

Richard Banker (1992) defined management information system as a comprehensive or overall integrated system for providing information to support the planning, control and operation of an organization or enterprises. Sports management in Nigeria Universities usually have a diverse range of information need. The integrated use of these several forms of information technology would allow these different needs to be met in an efficient and cost effective manner. Sport managers need to consider how these can best be used during University Games. For example, Universities can develop a website that can be used to communicate information about the organization to those inside or outside.

\section{Benefits of information and communication technology in sports management in Nigerian universities}

Information Technology is basically tools and methods used for the identification, organization and manipulation of facts that is called data. It is today a driving force in all sectors of the economy, industries, education and indeed sports. Information Technology in sport management system centres on technological revolution; internet and E-commerce mainly as vehicle for people to participate in sports through lower priced equipment. Universities are expected to hoist and manage sports website.

Technological Revolution: Information Technology is today, the engine house driving all sectors of the economy globally; be it in private or public sector - industries, government sectors/agencies and sports administration. Sports Managers, Directors or Coaches (as the case may be) can also use Information 
Technology (IT) to develop various services for members, such as e-newsletters, online application for merchandise or competition entries. For example, the Nigerian University Games Association introduced the use of Information Technology (IT) a web-site, web based, interactive information system that linked all the Nigerian Universities for the games held in the University of Benin in 2011. Online sport activity registration is important in University sports. At the Centre of Stage is the most important piece of equipment called "Computer".

The computer and the software that it runs is an essential element and a key to success for modern sport management. The secret to managing knowledge and information is in the development and maintenance of computer database.

Data Base: This is an organized collection of records that can be reached, accessed and modified. A relational database can be used by sports managers or coaches to store information in a series of tables consisting of rows and columns of data. Every information on a sports competition could be stored in the data - base; the time schedule for events can be pulled out; name of officials results. All these could take hours of manual manipulation from paper records but with computer database; and within seconds the information is out. Use of Information Technology is very necessary during NUGA games on year to year operation. It could be used by each University in Nigeria for her athletes specific information such as name, sex, age, contact information; level of student athlete in school, number of year he or she has been to and participated in NUGA games; also to authenticate his/her studentship; medical history etc. Fund is an issue for today's University Sport Management professionals. Database could be very useful for tracking donors or potential donors for their services. It could be very vital for general management of sports personnels.

Issues like accounting, keeping business records, employees files, equipment inventories or facility maintenance records could be handled in database. The organizational marketing information system is a typical database program in which information such as season ticket sales; gate receipts or merchandise sales are tracked.

Database could be regularly updated to record changes, bearing in mind that the passage of time presents a more comprehensive future of most activities. The ability to record changes in sports and making sense and corrections out of it is essential for long term survival of sports management globally. Although database are used for effective sports program management, the real power of information technology lies in the computer.

Computer: Computers are tied together through the medium of network. Today, apart from sports managers, most larger enterprises use computer networks to link their operations in a common computing environment. This network has a main server that houses most of the information and database files. Sports as a physically demanding profession, should use computer to help push sporting organizations towards their goal of success.

\section{Computer in sports administration and management}

Storing and Watching Sports Video: Video preparation is a major component of professional sports. For example many coaches, trainers and even athletes themselves review recorded competitions tapes to study some one performance at critical parts of a competition and thus learn. A boxer can review his next opponent's fight to learn weaknesses/strength to exploit; A football coach can review game tape to see how to improve his offensive passing/attack and improve on his game plan.

Computer also allow sports professionals to store a large amount of video footage in one place as against having multiple discs or cassettes of film; all these information could be stored in a single jump drive or laptop for easier access at short notice. 


\section{Statistical data storage}

Statistics are important aspect of sports organization and management. Fans, sports agents, coaches, players and the Universities administration; all wants to know exactly how well or bad they performed at any given time/year. Keeping a track record of that data by Managers/Directors of Sports is very necessary in sports management.

\section{Internet and sports management}

According to Atajeromavwo (2010) internet is interconnection of million of computer from one geographical location to another through the end of telecommunication system in other to accomplish sharing of information across the globe. It is important to note that computer networks need not be limited to a single site or facility. Wide Area Network can little together University Sports administrators located throughout the Federation. For example the zonal offices of a national sports governing body such as the Nigerian University Games Association can be linked together regardless of their geographic location. The operatives so linked can share information cheaply and effectively through the medium of e-mail. The computer network which the public is most familiar with is the internet and the worldwide web, known as the "web" and it is what most people think of when we say "the internet". This medium has exploded and today there are more than 15 million web addresses called Uniform Resources Locators (URLS) with many individual pages on their sites (Jessup, and Valacich, 2004).

Most significant at this juncture is the marketing and commerce application of the web. For example there are virtually no professional sports team in the United State today that do not have a website; most of them linked together through networks of website coordinated through the various league/offices. How tight these linkages are, is driven in part by agreement between the league teams on activities such as revenue sharing for media broadcasting rights and merchandise sales. The web is currently used by professional sports teams in so many ways. In montreal were there are no English language radio broadcasts, for their Expos professional baseball team, the fans who wants to hear the play by play in English language can only do so by calling up the team's website and listen to it coming across as an audio feed. Many clubs to require their players to have e-mail addresses as a means to interact with both the administrators and fans. This is in existence today in Nigerian University Games Association Council (NUGA).

E-Commerce: The web can change the sale and distribution of sporting equipments. Facilities which are central in the administration/running of sports programme in Universities. The relative cost for sports equipments can be an issue for the profession, particularly in terms of trying to broaden the appeal of sport to the greatest number of participants. It holds the potentials for containing.

Costs for Sports Equipment: In the traditional model of manufacture and distribution through a sporting goods store, it is not uncommon for a tennis racquet which cost N4,000 to manufacture to be marked up as much as 300 to $400 \%$ to as much as $160 \%$ as it moves through various wholesalers and retailers in the distribution chain to a tennis player. With an e-commerce arrangement whereby the manufacture can reach the buyer directly without going through middlemen, the mark - up in distribution can be reduced to as little as $50 \%$ of the traditional retail price resulting in a sale price to the end user of about N8,000. Very simply, the more middlemen in a distribution chain, the greater the benefit derived to the end user from using ecommerce distribution.

To set up information technology for sports management in Universities, the following items are required - Computer; internet connectivity; file servers; software to create database e.g oracle computer experts; computer analysis and programmes amongst others. 


\section{Conclusion}

The use of Information Communication Technology in sports management in Universities would lead to an efficient, speedy, easy standard and transparent dissemination of information in collective decision taking in the organization and management of sports. Sports management bodies are full of multiple departments and actors with specialized mandates that deliberate on issues of the sport management organization and come up with tangible results to enhance the implementation of information technology policy to meet the objectives and aspiration of University Sports organizations.

The requirements for the set-up of Information and Communication Technology in Sports Management system should be adhered to in order to accomplish the strategies and benefits of Information and Technology in our Universities.

\section{Recommendations}

1) University sports managements should setup their internet and website to serve as links between management, athletes, employees and the outside world.

2) Government and University administrators should provide the Information and Communication Technology infrastructures in colleges, and Universities/and also encourage staff for interactive online education course in sports management.

3) Management of Universities should subsides commercial internet café in their vicinities to enhance students access to modern tools in sports and sports management to enhance their performance.

4) Donations should be sought for the building of Information and Communication Technology centres for use of all concerned in sports management.

\section{References}

Ajeigbe, Y. I. and Abubakar, N. M. (2007) The Role of Sports Participation in Enhancing Health Reforms, Journal of Sports Management and Educational Research Vol.1 No.3 p31.

Atajeromavwo, E. J. (2010) Management Information System, System Analysis and Design with Modern Trend in Computer Technology, Bommo Publishers, Benin-City, Nigeria pp25 - 26.

Ikhioya, O. S. A. (2001) Functional Strategies for Effective Sports Management Practices. Guide for Sports Managers and Administrators. Lagos: Sports and Leisure Consults International Olympic Committee (1999).

Jessup, L. and Valacich, J. (2004) Information Today, Prentice Hall, New Jersey USA pp.1 - 10.

Loy, K. W. (1996) Sports and Social System: A Guide to the Analysis, Problems and Literature. New York: Addison Wesley Publishers.

Lucey T. (2004) Management Information Systems, Martin the Printer Ltd, Bernick Upon Tweed, London.

O'Brien, J. (2004) Management Information System. McGraw Irwin, New York in USA.

Ohiruntola, I. A. and Achugbu, P. (2002) Sports Management Techniques as a Function of National Development, Journal of Sport Management and Educational Research (I) pp. 54 - 58.

Oyeniyi, P. O. (2001) Funds for Effective Administration of School Sports in Nigeria.

Richard, B. (1992) Case Method for Oracle Relational Database Management System, Addison-Wesley Publication Company, England.

Wu and Wu M. (2005) Systems Analysis and Design, West Publishing Company, New York in USA p.8.

Rosandich, T. J.(2011) http://ww,thesportjournal.org/article/information-technology-sport-management.

Roger, Jackson (2010), Sport Administration Manual, The Lowe Martin Group Ottawa, Canada. p.239 - 243. 